Open Access

\title{
Gender differences in willingness to pay for capital-intensive agricultural technologies: the case of fish solar tent dryers in Malawi
}

\author{
Levison S. Chiwaula ${ }^{1 *}$, Gowokani Chijere Chirwa', Lucy S. Binauli ${ }^{2}$, James Banda ${ }^{3}$ and Joseph Nagoli4
}

\author{
* Correspondence: \\ Ichiwaula@yahoo.co.uk \\ 1 Department of Economics, \\ Chancellor College, University of \\ Malawi, P.O. Box 280, Zomba, \\ Malawi \\ Full list of author information is \\ available at the end of the article
}

\begin{abstract}
Gender differences in fish processors' willingness to pay for a group-owned fish solar tent dryer (FSTD) are being assessed by using the double hurdle model. Willingness to pay (WTP) responses from 382 randomly selected fish processors were elicited through a bidding game in a contingent valuation method. The findings show that the average probability that fish processors will be willing to pay was 74\% (76\% for females and $72 \%$ for males). Furthermore, the average level of WTP was US\$29.45 (US\$26.46 for females and US\$33.51 for males). Females have a lower level of WTP than men because of their low endowment with assets that can assist them such as education, access to markets and productive assets. In view of these findings, the paper concludes that female fish processors have a higher probability of being willing to pay than male fish processors, but the levels of WTP are lower for female processors. The study suggests that when organising the community into cooperatives is possible, WTP for capital-intensive technologies can be assessed as contributions of individuals to the total cost of the technologies although the common property characteristic is suspected to lower the level of willingness to pay.
\end{abstract}

Keywords: Fish postharvest losses, Fish solar tent dryer, Willingness to pay, Contingent valuation, Double hurdle model, Malawi

\section{Background}

The division of labour in artisanal fisheries in Africa is highly gendered, with men dominating the fishing operations and marketing of perceived high premium fish species (Coastal Resources Center 2016), whereas women dominate the processing and marketing of small fish species (Chiwaula et al. 2012; Nagoli and Chiwona-Karltun 2017). Women are not allowed to fish in open waters or be seen working with men in fishing (Chiwaula et al. 2012).

Although women are the major fish processors, their access to fish processing technologies seems to be limited due to unequal division of labour, limited incomes and time to manage fishery resources and other social injustices (Ngwira 2001; Chiweza 2005; GoM 2008). Women therefore end up drying fish on open-air racks (sun drying). The problem with this method is that it is associated with large physical and quality postharvest losses such as high microbial contamination and low sensory properties

(c) The Author(s). 2018 Open Access This article is distributed under the terms of the Creative Commons Attribution 4.0 International License (http://creativecommons.org/licenses/by/4.0/), which permits unrestricted use, distribution, and reproduction in any medium, provided you give appropriate credit to the original author(s) and the source, provide a link to the Creative Commons license, and indicate if changes were made. 
(Sablani et al. 2003; Banda et al. 2016) which are estimated at $27.3 \%$ in Africa (Affognon et al. 2015).

These losses have negative implications on fish supply and incomes of actors in the fish value chain particularly women who are involved in fish processing. The high postharvest losses also contribute to the global challenge of food loss and food waste as we think of feeding over 9.1 billion people with safe food by the year 2050 (Béné 2009; Parfitt et al. 2010; Affognon et al. 2015). It is reported that tackling postharvest waste and losses could add 15 million tonnes of fish to the food chain (FAO 2016).

In an effort to reduce fish postharvest losses, a fish solar tent dryer (FSTD) has been designed and is being promoted along Lake Malawi. A FSTD is a greenhouse-like structure that is made of wooden frame and is wrapped in ultraviolet (UV)-treated transparent polythene $200-\mu \mathrm{m}$ plastic sheet. Using FSTDs reduce postharvest losses, improve on sensory properties of the dried fish and reduce microbial contamination of the dried fish (Banda et al. 2016). An economic analysis of the dryer also shows that the solar tent dryer is profitable with an estimated net present value of MK6,014,489, has a payback period of 1.77 years and the internal rate of return of $55 \%$ which is greater than the cost of capital (Kawiya 2017). The dryer is economically viable because the price of solar dried fish is almost double the price of open sun-dried fish because of the improvements in quality and associated access to better markets. The solar tent dryer was first designed by Doe et al. (1977) in Bangladesh and was recently modified and used by Olokor and Omojowo (2009) in Nigeria.

Unlike the original solar dryers that were small and were not designed for commercial purposes, the dryer on Lake Malawi is large and has a capacity of up to $850 \mathrm{~kg}$ of fresh fish per drying cycle (see Fig. 1). The size of the dryer implies that most of the small-scale fish processors that are being targeted in the project cannot privately own a solar dryer.

Promotion of the fish solar tent dryers on Lake Malawi uses business approaches that encourage fish processors to demand the dryers unlike the convention of giving such capital technologies freely to the communities which undermine the sustainability of the interventions. Promotion of adoption of the dryers would therefore require adequate knowledge about economic incentives for fish processors to construct, own and use the fish solar tent dyers. Information about these economic incentives requires that we analyse the demand for the technology. Understanding the factors associated with the demand is important for the design of promotion strategies, and this involves the estimation of demand models that are normally based on observed demanded quantities and observed prices. In the absence of observed prices and quantities demanded, stated preference methods such as the contingent valuation methods (CVM) or choice experiments are used to assess demand (Diamond and Hausman 1994; Blumenschein et al. 2008). These methods are used to elicit preferences from potential users and buyers of goods and services.

In this paper, we analyse Lake Malawi fish processors' WTP and identify the gender disparities that are associated with the WTP for a common good, i.e. investing in a group owned fish solar tent dryer. We assessed the willingness to pay for group ownership of the FSTD because we assumed that the initial investments are too high for individual fish processors to bear. However, we note that common ownership of FSTD would bring with it low security of ownership which has been documented to have a negative influence on a long-term investment (Ayamga et al. 2016). We therefore expect this insecurity to influence their willingness to pay as well. 

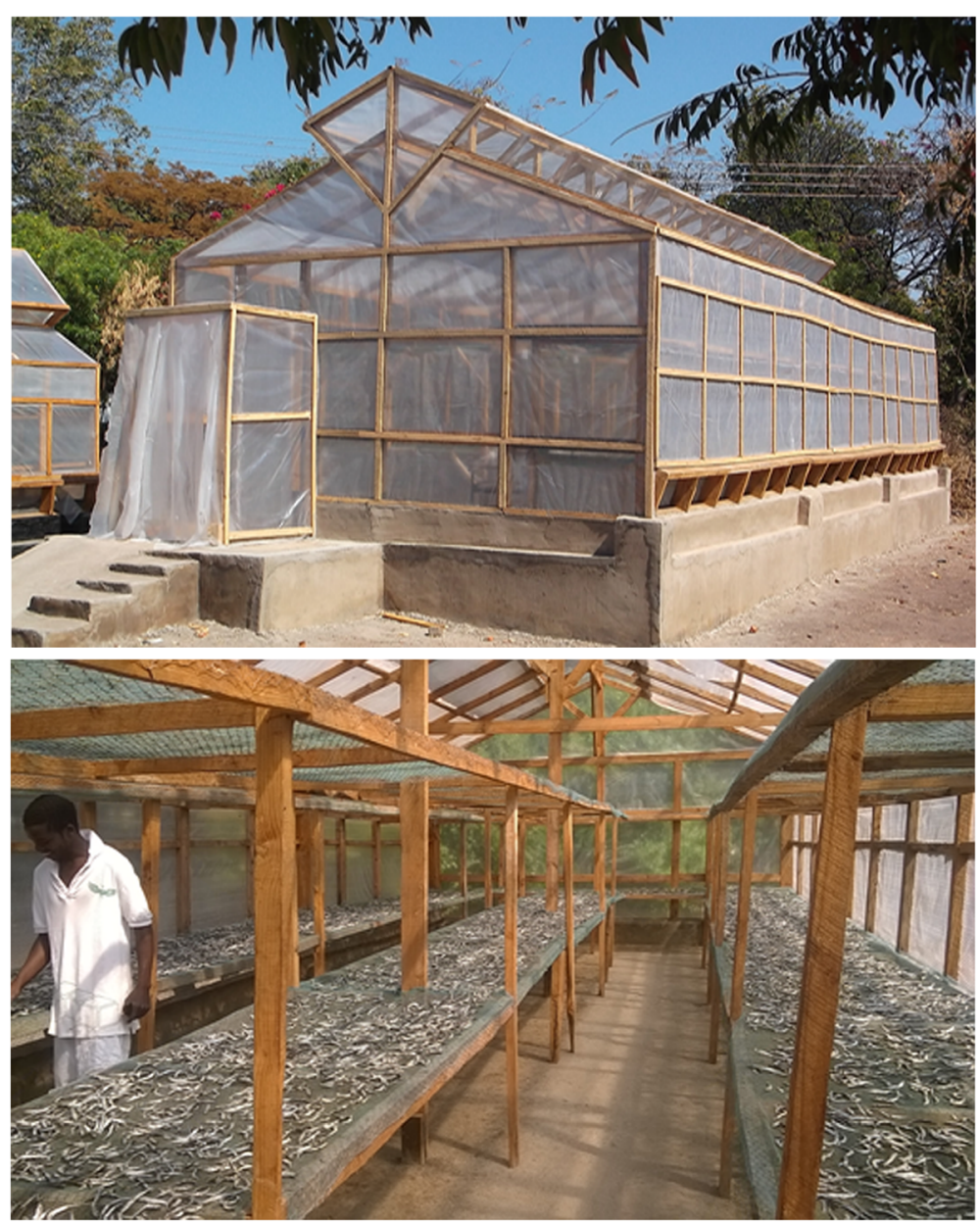

Fig. 1 Picture of the outside (upper) and inside (lower) view of a fish solar tent dryer

This information has helped to better understand women's and men's decisionmaking as regards to accessing and benefiting from improved postharvest fish processing technologies. The knowledge on how gender and other forms of social differentiation affect and are affected by development processes can lead to unintended program consequences and/or the perpetuation of universalising myths about men's and women's roles in development, such as women's concentration in small fisheries processing versus commercial fishing and their greater altruism. It also can lead to the treatment of women and men as monolithic groups. All of these are risks that value chain development should aim to avoid.

\section{Methods}

\section{Study area and design}

This is a cross-sectional study implemented as part of the baseline survey for "Improved processing and marketing of healthy fish products in Malawi", of one of the Cultivate Africa's Future (CultiAF) projects. The project is aimed at adapting and promoting fish solar dryers in Salima and Mangochi districts in the southern part of Lake 
Malawi. This paper uses a subsample of the baseline survey data on fish processors only. Five study sites from the two districts (Madzedze; Malembo and Msaka in Mangochi; and Chikombe and Lifuwu in Salima) were selected purposively based on their high production levels of small fish species.

Size for the entire baseline survey, the sample size calculation was derived using the Cochran method (Cochran 1977):

$$
n=z_{1-\frac{\alpha}{2}}^{2} p(1-p) / d^{2}
$$

Where $n$ is the sample size; $z$ is a $z$-score assumed to be 1.96 , to correspond to the 95\% level of confidence; $\alpha$ is the probability of making type 1 error and set at $5 \%$ (this is the standard); $p$ is the proportion of respondents responding in a particular way to the level of knowledge of current processing practices which was assumed to be at 0.5 because the population proportion $(p)$ is not known; and $d$ is the absolute margin of error (level of accuracy) assumed equal 0.045 or 0.05 (to 2 decimal places), when the population $(p)$ is not known (Cochran 1977; Lwanga and Lemeshow 1991). The sample was adjusted upwards to account for a 15\% loss to follow-up during end line survey and a non-response rate of $10 \%$. This resulted in a total sample of 509 fish value chain actors which were identified randomly and was distributed in fishing sites proportional to size. From this sample, 382 respondents were fish processors and this paper is based on these. The study protocol and the questionnaire were approved by the National Committee on Research in the Social Sciences and Humanities (NCRSH). Written consents were sought from all participants during data collection.

\section{Theoretical model}

The willingness-to-pay decisions are assumed to be driven by the utility the fish processors expect to obtain from the use of solar tent dryers through the expected net incomes and other benefits such as reduction in drudgery. The expected utility of using solar tent dryers by the fish processor $i U_{\text {is }}$ is different from the expected utility of using the current technology (open sun drying) $\left(U_{\mathrm{io}}\right)$. The two utility functions can be given as:

$$
\begin{aligned}
& U_{\mathrm{is}}=\beta_{\mathrm{s}} x_{\mathrm{is}}+\varepsilon_{\mathrm{is}} \\
& U_{\mathrm{io}}=\beta_{\mathrm{o}} x_{\mathrm{io}}+\varepsilon_{\mathrm{io}}
\end{aligned}
$$

where $x_{\mathrm{ij}}$ stands for a vector of attributes of technology $j$ and characteristics of the fish processor $i, \beta_{0}, \beta_{\mathrm{s}}$ are the parameters that measure the marginal contribution of the attributes and $\varepsilon_{\mathrm{ij}}$ stands for random variables. The inclusion of the random component in the utility functions enables us to apply the random utility theory (Lancaster 1966; McFadden 1980; McFadden 1984; Greene 2008). Technology attributes may include the effects of solar dryers on fish postharvest losses (qualitative and quantitative), organoleptic characteristics of the fish and drudgery associated with the two technologies. These technology attributes influence net incomes from fish processing which are expected to enter the utility function through the purchase of inputs into the production of utility-enhancing commodities, such as meals and leisure. Fish processors will be willing to pay for solar dryers if $U_{\mathrm{is}}-U_{\mathrm{io}}=\Delta U_{\mathrm{i}}>0$ thus; 


$$
U_{\mathrm{is}}=\beta_{\mathrm{s}} x_{\mathrm{is}}+\varepsilon_{\mathrm{is}}>U_{\mathrm{io}}=\beta_{\mathrm{o}} x_{\mathrm{io}}+\varepsilon_{\mathrm{io}}
$$

The change in utility resulting from the use of solar dryers cannot be observed, but this can be defined as a latent variable, $W T P_{i}^{*}$, which is observed when is $\Delta U_{i}>0$. The latent variable can then be defined as:

$$
\mathrm{WTP}_{\mathrm{i}}^{*}=\left(\beta_{\mathrm{s}}-\beta_{\mathrm{o}}\right)\left(x_{\mathrm{is}}-x_{\mathrm{io}}\right)+\varepsilon_{\mathrm{i}}=\beta x_{\mathrm{i}}+\varepsilon_{\mathrm{i}}
$$

Equation 4 implies that although we are not able to observe the change in utility, the stated WTP can be used as an indicator for the change in utility.

\section{Data}

Data was collected using a semi-structured questionnaire that contained a socioeconomic and production data. In collecting WTP data, we used the contingent valuation method (CVM). CVM is a survey-based economic technique for the valuation of non-market resources, typically environmental attributes and amenities (Cho et al. 2008). Among the many methods, WTP can be elicited by using open-ended questions or close-ended questions (Carlsson and Martinsson 2007) and several factors that affect the choice of elicitation technique (Carson et al. 1996; Horowitz and McConnell 2002; Venkatachalam 2004; Solgaard and Yang 2011). In eliciting the information on WTP, a description of a solar tent dryer was first given to the fish processors. The information included the expected cost of the solar tent dryer. Fish processors were then asked whether they were willing to contribute money to construct a solar tent dryer that will be owned by a group of fish processors. Processors who indicated that they were willing to pay were then asked openended questions on the amount of money they were willing to pay. The stated values were bided upwards until the maximum value was established. Table 1 presents the descriptive statistics of fish processors that were involved in the study.

The distribution of the sample across study sites shows that most processors in our sample came from Madzedze (119), and this was followed by Malembo (95) and Msaka (94). Most of the respondents were female (58\%), and the average age was 38 years. The average education attainment is 3.0 ( 2.7 for females and 3.2 for males) implying that most of the respondents had attained senior primary school education. Most fish processors sold fish at distant markets (86\%) compared to fish processors that sold fish at the fish processing site (8\%) or in a local market (5\%).

In terms of financial capacity, about $36 \%$ of the fish processors had a savings account with a bank. The descriptive analysis also reveals that the respondents had fishing and fish processing assets of substantial value with males having more fishing assets than females and females having more fish processing assets than males. By the time we were collecting baseline data, only $14 \%$ (16\% of females and $12 \%$ of males) of the fish processors ever heard of solar tent dryers.

\section{Model selection and estimation}

WTP was modelled as a two-stage decision process. In the first stage, fish processors decide on whether they were willing to pay or not (participation stage). In the second stage, fish processors who decided to pay made decisions on the amount of money they were willing to pay. The two-step decision-making process generated censored data 
Table 1 Descriptive statistics of fish processors in Mangochi and Salima districts in Malawi

\begin{tabular}{|c|c|c|c|c|c|c|}
\hline \multirow[t]{2}{*}{ Variable } & \multicolumn{2}{|c|}{ Female $(n=220)$} & \multicolumn{2}{|c|}{ Male $(n=162)$} & \multicolumn{2}{|c|}{ Whole sample $(n=382)$} \\
\hline & Mean & Std. dev. & Mean & Std. dev. & Mean & Std. dev. \\
\hline \multicolumn{7}{|l|}{ Dependent variables } \\
\hline Level of WTP (MK) & $15,379.55$ & $19,906.70$ & $16,990.88$ & $19,119.52$ & $16,062.88$ & $19,567.59$ \\
\hline Willing to pay $(1 / 0)$ & 0.76 & 0.43 & 0.72 & 0.45 & 0.74 & 0.44 \\
\hline \multicolumn{7}{|l|}{ Explanatory variables } \\
\hline Age (years) & 37.482 & 11.095 & 37.815 & 10.440 & 37.623 & 10.809 \\
\hline Married (1/0) & 0.768 & 0.423 & 0.877 & 0.330 & 0.814 & 0.390 \\
\hline Education attainment (count) & 2.723 & 1.098 & 3.259 & 1.214 & 2.950 & 1.177 \\
\hline Processing site market $(1 / 0)$ & 0.086 & 0.282 & 0.074 & 0.263 & 0.081 & 0.273 \\
\hline Local market $(1 / 0)$ & 0.050 & 0.218 & 0.062 & 0.241 & 0.055 & 0.228 \\
\hline Distant market $(1 / 0)$ & 0.836 & 0.371 & 0.858 & 0.350 & 0.846 & 0.362 \\
\hline Own savings account $(1 / 0)$ & 0.359 & 0.481 & 0.370 & 0.484 & 0.364 & 0.482 \\
\hline Knowledge & 0.159 & 0.367 & 0.123 & 0.330 & 0.144 & 0.352 \\
\hline Self-income decisions $(1 / 0)$ & 0.345 & 0.477 & 0.525 & 0.501 & 0.421 & 0.494 \\
\hline In (fishing assets) & 2.266 & 4.986 & 3.490 & 5.920 & 2.785 & 5.428 \\
\hline In (processing assets) & 8.259 & 3.619 & 7.253 & 5.127 & 7.832 & 4.345 \\
\hline Madzedze & 0.427 & 0.496 & 0.154 & 0.362 & 0.312 & 0.464 \\
\hline Malembo & 0.173 & 0.379 & 0.352 & 0.479 & 0.249 & 0.433 \\
\hline Msaka & 0.309 & 0.463 & 0.160 & 0.368 & 0.246 & 0.431 \\
\hline Chikombe & 0.005 & 0.067 & 0.136 & 0.344 & 0.060 & 0.238 \\
\hline Lifuwu & 0.086 & 0.282 & 0.198 & 0.399 & 0.134 & 0.341 \\
\hline
\end{tabular}

Source: computed by the authors

that have a large proportion of zeros for individuals that are not willing to pay and continuous values for individuals that are willing to pay. The zeros should, without any further information, be treated as true zeros (corner solutions) since we cannot rule out a zero WTP (Carlsson and Martinsson 2007). There is, however, a possibility that some of the zeros could be "protest" zeros. In the case of protest zeros, respondents report zero WTP but their marginal value of the commodity might be positive, perhaps because they think other agents such as the government, rather than themselves, should pay for the provision of the commodity (Yu and Abler 2010). In the case of fish processors, there may be a reasonable expectation that the government will provide solar tent dryers to the communities for free because the government with some development partners have been providing improved fish processing technologies such as the ice making plant for free. Some members of the community may therefore consider reporting a positive WTP as a disincentive to the government to provide fish solar tent dryers for free. There was also a possibility of selection problem as has been pointed out in other CVM studies (Brox et al. 2003). Selection would exist if individuals with particular characteristics report zero willingness to pay. This means that WTP can be modelled through a standard Tobit model, the Heckman selection model or a double hurdle model depending on the assumptions that are made about the observed zero WTP values.

The standard Tobit model (Tobin 1958) is supposed to be used when the observed zeros represent corner solutions and this was tested by using the log likelihood ratio 
test (Martínez-Espiñeira 2006) whose null hypothesis is that the Tobit model is the correct specification. The chi-square statistic for this test was derived as follows:

$$
\text { LR statistic }=-2\left[\ln L_{\mathrm{T}}-\left(\ln L_{\mathrm{p}}+\ln L_{\mathrm{TR}}\right)\right] \sim \chi_{\mathrm{k}}^{2}
$$

Where $\ln \mathrm{L}_{\mathrm{T}}$ is the $\log$ likelihood for the Tobit model, $\ln \mathrm{L}_{\mathrm{p}}$ is the $\log$ likelihood for the probit model, $\ln _{\mathrm{TR}}$ is the $\log$ likelihood for the truncated regression and $k$ is the number of independent regressors in the equations. The probit model and the truncated regression form the double hurdle model. Choices on variables to be in the selection model and the level model were made on the assumption that level of information and exposure by the respondent will influence the decision to participate or not but the wealth of the respondent will influence the amount of money they are willing to pay. Applying Eq. 6 to the results presented in Appendix 1 gives us a LR statistic that is equal to 845.81 thereby rejecting the Tobit model in favour of the Heckman two-step selection model (Heckman 1979) or the double hurdle model (Cragg 1971).

To decide between the Heckman selection model and the double hurdle model, we followed $\mathrm{Yu}$ (1996) who proposed a test that use collinearity between the regressors in the level equation of a Heckman selection model and the inverse Mills ratio (IMR). The collinearity limits the power of the $t$ test for sample selectivity on the coefficient of the IMR (a test which is sometimes used as a criterion for model selection) (Madden 2008). The findings in the collinearity test which involves the regression of the IMR on all the regressors (not reported) show that the IMR is highly collinear with the regressors with an estimated R-squared of 0.67. This is greater than 0.30, a threshold suggested by Belsley (1991). Results of the Heckman selection model (Appendix 1) also weakly confirm the existence of selection problem at $10 \%$ level of significance. For this reason, we proceeded with the double huddle model.

\section{The double hurdle model}

The two-step decision on the WTP for the fish solar tent dryers was therefore modelled by using the double hurdle model (Cragg 1971). Double hurdle also performs better than standard OLS (Donaldson et al. 1998). Furthermore, unlike the standard Tobit model (Tobin 1958) in which the probability of a positive value and the actual value, given that it is positive, are determined by the same underlying process, the double hurdle model allows these outcomes to be determined by separate processes through a probit model in the first process and the truncated normal model in the second process (Burke 2009). This has mostly been used in studies analysing expenditure of infrequently purchased commodities (Newman et al. 2003) as well as WTP studies (Yu and Abler 2010). The double hurdle model is specified as:

$$
\begin{array}{lll}
\mathrm{WTP}_{1 i}^{*}=\beta_{1} x_{\mathrm{i}}+\varepsilon_{\mathrm{i}} & \varepsilon_{\mathrm{i}} \sim N(0,1) & \text { Participation equation } \\
\mathrm{WTP}_{2 i}^{*}=\beta_{2} x_{\mathrm{i}}+v_{\mathrm{i}} & v_{i} \sim N\left(0, \sigma^{2}\right) & \text { Level of WTP } \\
\mathrm{WTP}_{i}=\beta x_{\mathrm{i}}+u_{\mathrm{i}} & & \text { if } \mathrm{WTP}_{1 i}^{*}>0 \text { and } \mathrm{WTP}_{2 i}^{*}>0 \\
\mathrm{WTP}=0 & & \text { Otherwise }
\end{array}
$$

where $\mathrm{WTP}_{1 i}^{*}$ and $\mathrm{WTP}_{2 i}^{*}$ are latent variables for the decision to pay or not for solar tent dryers, and latent variable describing the amount of money the fish processor is 
willing to pay; WTP is the stated willingness to pay; $\varepsilon_{\mathrm{i}}$ and $v_{\mathrm{i}}$ are error terms that are assumed to be independent and normally distributed (Greene 2008). Common problems with the estimation of the second equation that takes a form of a Tobit model are heteroscedasticity and non-normality of error terms which may result in loss of efficiency and inconsistency of estimates, respectively. To solve this problem, we allowed the error variance of the Tobit model to vary across observations as well as applying the inverse hyperbolic sine transformation (IHS) to the dependent variable (Newman et al. 2003; Sinnig 2011). The IHS transformation is defined as (Burbidge et al. 1988):

$$
\mathrm{WTP}_{i}^{I H S}=\ln \left(\theta \mathrm{WTP}_{\mathrm{i}}+\left(\theta^{2} \mathrm{WTP}_{\mathrm{i}}^{2}+1\right)^{1 / 2}\right) / \theta
$$

where $\theta$ is a parameter that can be estimated from the data and has been assumed to be equal to unity in practice (Sinnig 2011), which we follow. The likelihood function for the independent double hurdle model allowing for heteroscedasticity and nonnormal error structure can thus be given as (Newman et al. 2003):

$$
\left.L=\prod_{0}\left[1-\Phi\left(\beta_{1} x_{i}\right) \Phi\left(\frac{\beta_{2} x_{i}}{\sigma_{i}}\right)\right] \times \prod_{1}\left[1+\theta^{2} \mathrm{WTP}^{2}\right)^{-1 / 2}\left(\frac{\Phi\left(\beta_{1} x_{i}\right)}{\sigma_{i}}\right) \phi\left(\frac{\mathrm{WTP}_{i}^{I H S}-\beta_{2} x_{i}}{\sigma_{i}}\right)\right]
$$

where $\Phi$ is the standard normal cumulative distribution function, and $\phi$ is the standard normal probability distribution function. The log likelihood function derived from Eq. 7 was maximised by applying the craggit command (Burke 2009) on the IHS-transformed dependent variable and independent variables in Stata version 13 (Stata Corp). Basing on this likelihood function, the probability on whether the fish processor is willing to pay is given as:

$$
P\left(\operatorname{WTP}_{i}>0 \mid x_{i}\right)=\Phi\left(\beta_{1} x_{i}\right)
$$

The expected value of $W T P_{i}^{I H S}$ conditional on $W T P_{i}^{I H S}>0$ is given as

$$
E\left(\mathrm{WTP}_{i}^{\mathrm{IHS}} \mid \mathrm{WTP}_{i}^{\mathrm{IHS}}>0, x_{\mathrm{i}}\right)=\left(\beta_{2} x_{\mathrm{i}}\right)+\sigma_{\mathrm{i}} \times \lambda\left(\beta_{2} x_{\mathrm{i}}\right)
$$

where $\lambda\left(\beta_{2} x_{\mathrm{i}}\right)$ is the inverse Mills ratio (IMR). With some algebraic manipulations, we can derive the following expression for the expected value of WTP from Eq. 8.

$$
\mathrm{WTP}=\sqrt{\frac{\left(\exp \left(E\left(\mathrm{WTP}_{i}^{\mathrm{IHS}}\right)\right)^{2}-1\right)}{2}}
$$

\section{Results}

Results of the inverse hyperbolic sine transformation (IHS) are presented in Table 2.

Wald statistic shows that the model fits the data significantly. The heteroscedasticity in the second WTP level equation is also confirmed by the significant variables in the heteroscedasticity model, and this means that if we had not allowed for this, we would have large variances thereby making hypothesis testing difficult. Dummy variables for the fish landing sites are statistically significant, which signify the existence of site-level 
Table 2 Estimation results of the IHS double hurdle model for willingness to pay

\begin{tabular}{|c|c|c|c|c|c|c|}
\hline \multirow[t]{2}{*}{ Variable } & \multicolumn{2}{|c|}{ Participation } & \multicolumn{2}{|c|}{ Level of WTP } & \multicolumn{2}{|c|}{ Heteroskedasticity } \\
\hline & Coef. & $z$ & Coef. & $z$ & Coef. & $z$ \\
\hline Age & $-0.015^{* *}$ & -2.13 & $0.108^{* * *}$ & 2.88 & 0.005 & 1.29 \\
\hline Age squared & & & $-0.001^{* * *}$ & -2.71 & & \\
\hline Female & -0.105 & -0.60 & 0.126 & 0.95 & 0.042 & 0.65 \\
\hline Married & $-0.403^{*}$ & -1.82 & & & -0.305 & $-2.56^{* *}$ \\
\hline Education attainment & -0.019 & -0.28 & $0.165^{* * *}$ & 2.79 & & \\
\hline Local market & -0.308 & -0.84 & $0.618^{*}$ & 1.92 & & \\
\hline Distant market & 0.337 & 1.41 & $0.374^{*}$ & 1.72 & & \\
\hline Knowledge & $0.557^{* *}$ & 2.38 & & & & \\
\hline Own savings account & $-0.279^{*}$ & -1.72 & -0.005 & -0.04 & 0.022 & 0.25 \\
\hline In (fishing assets) & & & $0.021^{*}$ & 1.83 & & \\
\hline In (fish processing assets) & & & 0.015 & 1.12 & & \\
\hline Make decisions on income & $-0.365^{* *}$ & -2.15 & & & -0.063 & -0.72 \\
\hline Madzedze & 0.046 & 0.17 & $-0.821^{* * *}$ & -4.90 & 0.269 & $1.93^{*}$ \\
\hline Malembo & $-0.438^{*}$ & -1.71 & $-0.455^{* *}$ & -2.64 & 0.292 & $2.14^{* *}$ \\
\hline Msaka & $-0.425^{*}$ & -1.68 & $-0.828^{* * *}$ & -4.57 & 0.277 & $1.88^{*}$ \\
\hline Chikombe & -0.360 & -0.99 & -0.313 & -1.22 & 0.246 & 1.35 \\
\hline Constant & $1.854^{* * *}$ & 3.25 & $7.572^{* * *}$ & 9.44 & 0.739 & $4.74^{* * *}$ \\
\hline Number of observations & & & 382 & & & \\
\hline Wald chi $^{2}$ (13) & & & $28.89^{* * *}$ & & & \\
\hline Log likelihood & & & -581.36 & & & \\
\hline
\end{tabular}

***Denotes statistically significant at $1 \%$

**Denotes statistically significant at $5 \%$

*Denotes statistically significant at $10 \%$

heterogeneity in the decisions on WTP as well as the level of WTP. The inclusion of these has therefore assisted in improving the fit of the model. The results from the model were used to estimate the average probability that fish processors will be willing to pay and the average level of willingness to pay, and these are presented in Table 3.

For the whole sample, the average probability that fish processors will be willing to pay from the model was $74 \%$, and this is similar to the observed proportion of individuals that stated that they are willing to pay. The findings show that the probability of being willing to pay was significantly higher for female fish processors than it was for male fish processors, and their distribution is presented in Fig. 2. The distribution functions show that the higher average probability of being willing to pay among female fish

Table 3 Estimated probability and level of WTP

\begin{tabular}{lllll}
\hline Variable & Mean & & & \multirow{2}{*}{ t statistic } \\
\cline { 2 - 4 } & Female & Male & All & $3.02^{* * *}$ \\
\hline Probability of WTP & 0.76 & 0.72 & 0.74 & $4.72^{* * *}$ \\
Level of WTP (MK) & $19,316.13$ & $24,465.33$ & $21,499.82$ & \\
\hline
\end{tabular}

Exchange rate 1 US\$ to $730 \mathrm{MK}$

***Denotes statistically significant at $1 \%$

**Denotes statistically significant at 5\%

*Denotes statistically significant at $10 \%$ 


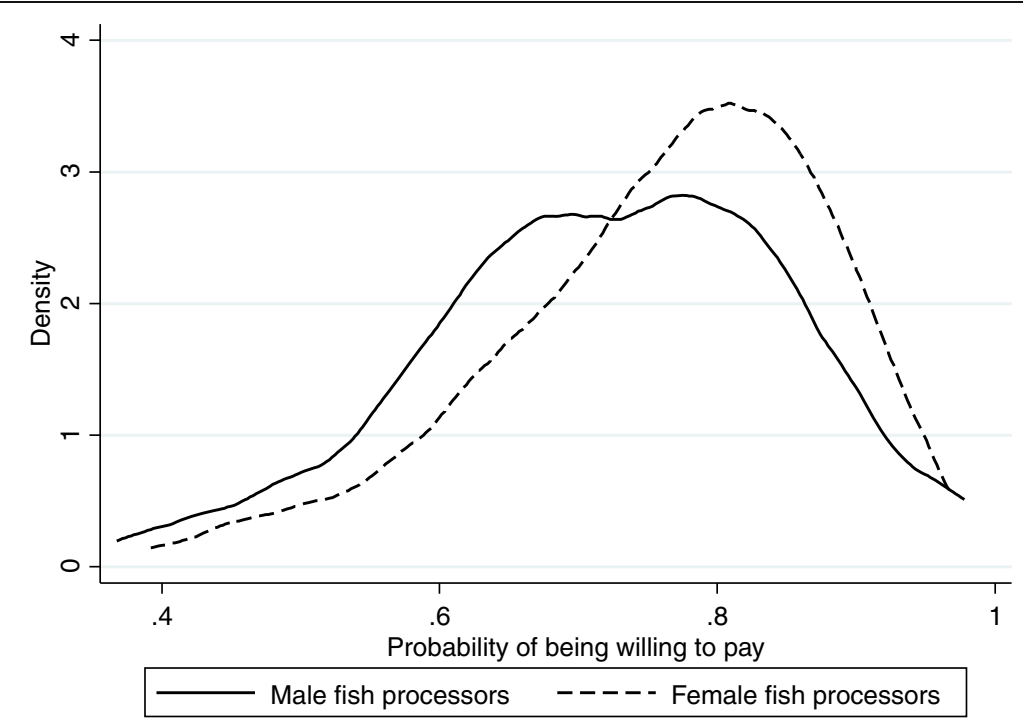

Fig. 2 Distribution of male and female fish processors' probability of stating a positive willingness to pay

processors is an outcome of a higher proportion of female fish processors with high probabilities of being willing to pay than the proportion of male processors with similar probabilities. This means that more female processors had a high likelihood of paying for solar tent dryers.

When it comes to the level of WTP, the results show that the observed willingness to pay was MK16,063 (about US\$22.00) while the estimated WTP (MK21,500 about US\$29.45). The level of WTP was higher for male fish processors than it was for female fish processors. The distribution of the estimated level of willingness to pay is presented in the kernel density function in Fig. 3.

The figure reveals that the distribution of the level of both male and female fish processors' WTP is skewed to the left. The distribution of the level of WTP of female fish

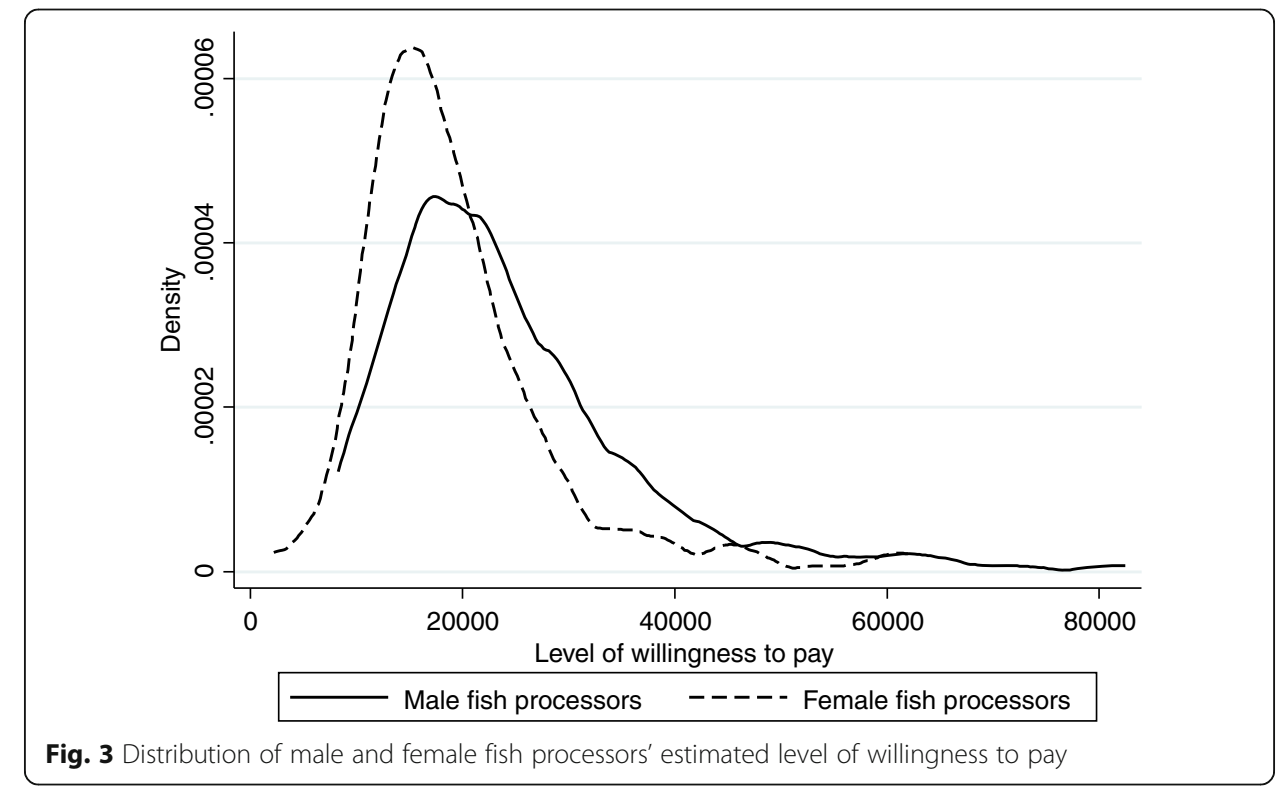


processors is more skewed to the left than that for their male counterparts implying that most of them were willing to pay lower amounts.

In assessing the determinants of willingness to pay, the results in Table 2 surprisingly show that sex of the fish processor is insignificant in both the participation and level equation. Age of the respondent has a linear negative relationship with the participation decision and a quadratic relationship with the level of WTP. This means that the likelihood that a fish processor would be willing to pay to construct a solar dryer reduces with age but the amount that fish processors are willing to pay increases at a decreasing rate with age. The negative relationship between the probability of being willing to pay and age has also been established in the adoption study by others (Zongo et al. 2015). It was also found that being married is associated with lower likelihood of being willing to pay for solar tent dryers. These findings also agree with a previous study that found that knowledge of the technology has a positive influence on willingness to pay (Padi et al. 2015). In our study, knowledge was assessed by asking the fish processors to indicate whether they have ever heard of solar dryers. We found that knowledge had a positive significant influence on the participation decision. This can also be implied by the influence of education in decision-making which our study also found a positive significant influence on the level of WTP.

We also found it necessary to test if the type of market where the fish was sold had significant influences on the participation as well as the level of the willingness to pay. Some fish processors sold the fish at the fish processing site, others at a local market and others sold fish at a distant market that operates on a daily basis or on a weekly basis. Considering selling fish at the processing site as the base category, we found that fish processors that sold fish at the local market and distant markets had a higher average level of WTP than those that sold fish at the processing site. The high demand for solar tent dryers among these fish processors may be influenced by their commercial approach to the fish processing business that influenced them to sell fish at more lucrative markets.

\section{Discussion}

This study was implemented within a broader project that aimed at increasing healthy fish supply and incomes of actors along the fish value chain through the promotion of fish solar tent dryers. Presently, the effectiveness (Banda et al. 2016) and the economic viability (Kawiya 2017) of the fish solar tent dryers have been established. This means that solar tent dryers are an important innovation because they reduce quality losses which impact on food safety, nutritional value and often economic value as successful markets depend on a consistent supply of good quality produce (Affognon et al. 2015). These benefits can be transferred to consumers and fish processors if the technology is widely adopted and hence need to assess willingness to pay.

The study estimated that fish processors have an estimated average probability of being willing to pay of $74 \%$ and an estimated average level of willingness to pay MK21,499.82 (about US\$29.45). The estimated cost of constructing a fish solar tent dryer (FSTD) largely depends on the size, and the cost of the present designs ranges from MK120,000 (about US\$167) to MK1,200,000 ( US\$1700). The 
capacity of the small FSTD can maximally be used by three fish processors implying that each should contribute about US $\$ 55$ to construct it while the large FSTD can ably support ten fish processors that means each should contribute about US\$170 to construct it. Clearly, there are disparities between the required capital investments and the levels of willingness to pay which may partly be attributed to high poverty levels in fishing communities (Béné 2009). The low levels of willingness to pay may also be attributed to the promotion of FSTD as a common property, which reduces the level of security attached to the investment, and level of investment among farmers are likely to make (Ayamga et al. 2016). Even if individuals contribute to the construction of the FSTD, the sustainability of the use of the dryer will not be guaranteed because it is known that individuals that are jointly using a common property have incentives to ignore the external harm they impose on others, leading to outcomes that are not rational from the perspective of the group (Gordon 1954). These findings suggest that the demand for solar tent dryers is high, but most fish processors would not afford to construct them.

One of the important findings from the study is that the study finds that sex of the respondents is not an important determinant both in the participation in WTP and the level WTP equations. However, the estimated probability of being willing to pay and the level of WTP are found to be significantly different between men and women. Women have a higher probability of being willing to pay than men, but their level of WTP is lower than that for men. These findings suggest that being a woman or a man does not bring differences in WTP but the differences in their endowments that are associated with WTP. Women have more of the endowments that are associated with high probability of being willing to pay such as knowledge of the solar tent dryer, while men have more of the endowments that are associated with high level of WTP such as education, selling to distant markets and fishing assets. This agrees with earlier studies that have shown that the mostly low-resourced women that are involved in pre- and postharvesting of fish (Chiwaula et al. 2012; FAO 2016). The low asset level for women leads to low levels of willingness to pay because they generally have limited access to incomes and other social resources (Ngwira 2001; Chiweza 2005; GoM 2008) which need to be addressed if meaningful development is to be achieved in the fish value chain. Some of the initiatives to consider would be to expand financing options such as village savings and loans (VSLs) and empowering the women through gender transformative approaches (GTA). The GTA would improve the control of women over resources and markets, and this will assist them in the adoption of FSTD.

The positive relationship between knowledge of solar tent dryers and the WTP for the FSTDs implies that creating more awareness would increase both the probability and the amount that fish processors are willing to pay. Awareness creation activities would likely help to reduce the disparity between the amount the fish processors are willing to pay and the cost of the technology. The negative relationship between age and probability of being willing to pay and the quadratic relationship between age and the level of willingness to pay show that solar tent dryers can be used to empower the youth because of their higher willingness to pay. Programs that aim at economically empowering the youth in fishing communities in Malawi and other similar settings can use solar tent dryers to achieve their intended outcomes. 


\section{Conclusions}

This paper has shown that many fish processors from Lake Malawi are willing to contribute money to co-own a solar tent dryer. More importantly, female fish processors have a higher probability of contributing than male fish processors, but the amounts they are willing to contribute are less than what males are willing to pay not because they are female but they are poorly endowed with resources that will make them have a high willingness to pay. The main challenge with the promotion of the technology rests on the fact that the amount of money that fish processors are willing to pay to contribute and co-own a fish solar tent dryers in a group is lower than the estimated cost of constructing the dryer. The study has also shown that when organising the community into cooperatives is possible, willingness to pay for capital-intensive technologies can be assessed as a contribution of an individual to the total cost of the technologies although the common property characteristic is suspected to lower the level of willingness to pay.

\section{Appendix 1}

Table 4 Estimated models for model selection tests

\begin{tabular}{|c|c|c|c|c|c|c|c|c|}
\hline \multirow[t]{2}{*}{ Variable } & \multicolumn{2}{|l|}{ Tobit } & \multicolumn{2}{|l|}{ Probit } & \multicolumn{2}{|c|}{ Truncated regression } & \multicolumn{2}{|l|}{ Heckman } \\
\hline & Coef. & $t$ & Coef. & $z$ & Coef. & $z$ & Coef. & z \\
\hline Age & 0.219 & 1.21 & $-0.015^{* *}$ & -2.13 & 0.085 & 2.46 & $0.091^{* *}$ & 2.63 \\
\hline Age squared & -0.003 & -1.54 & & & -0.001 & -2.38 & $-0.001^{* *}$ & -2.38 \\
\hline Female & 0.358 & 0.39 & -0.105 & -0.60 & 0.055 & 0.41 & 0.039 & 0.25 \\
\hline Married & & & -0.403 & $-1.82^{*}$ & & & & \\
\hline Education attainment & 0.140 & 0.47 & -0.019 & -0.28 & 0.147 & 2.63 & $0.157^{* *}$ & 2.42 \\
\hline Local market & -0.765 & -0.46 & -0.308 & -0.84 & 0.677 & 2.09 & $0.885^{* *}$ & 2.31 \\
\hline Distant market & $1.873^{*}$ & 1.78 & 0.337 & 1.41 & 0.517 & 2.58 & 0.356 & 1.44 \\
\hline Knowledge & & & 0.557 & $2.38^{* *}$ & & & & \\
\hline Own savings account & -0.858 & -1.19 & -0.279 & $-1.72^{*}$ & 0.036 & 0.27 & 0.169 & 0.99 \\
\hline Make decisions on income & & & -0.365 & $-2.15^{* *}$ & & & & \\
\hline In (Fishing assets) & -0.067 & -1.08 & & & 0.022 & 1.84 & $0.024^{* *}$ & 2.03 \\
\hline In (Fish processing assets) & -0.072 & -0.96 & & & 0.011 & 0.79 & 0.008 & 0.59 \\
\hline Madzedze & -0.483 & -0.46 & 0.046 & 0.17 & -0.802 & -4.2 & $-0.805^{* * *}$ & -3.56 \\
\hline Malembo & $-2.359^{* *}$ & -2.24 & -0.438 & $-1.71^{*}$ & -0.497 & -2.57 & -0.279 & -1.09 \\
\hline Msaka & $-2.154^{* *}$ & -2.00 & -0.425 & $-1.68^{*}$ & -0.814 & -4.08 & $-0.598^{* *}$ & -2.30 \\
\hline Chikombe & -1.322 & -0.86 & -0.360 & -0.99 & -0.425 & -1.51 & -0.261 & -0.77 \\
\hline Lambda & & & & & & & $-1.128^{*}$ & -1.87 \\
\hline Constant & 4.095 & 1.05 & 1.854 & $3.25^{* * *}$ & 8.054 & 10.44 & $8.240^{* * *}$ & 10.09 \\
\hline Number of observations & 382 & & 382 & & 284 & & 382 & \\
\hline LR/Wald Chi-square & $25.34^{* *}$ & & $31.61^{* * *}$ & & $62.17^{* * *}$ & & $51.27^{* * *}$ & \\
\hline Log likelihood & -1008.58 & & -201.712 & & -383.964 & & & \\
\hline Pseudo $R^{2}$ & 0.0124 & & 0.0752 & & & & & \\
\hline
\end{tabular}

The same probit model has been used as a selection equation in the Heckman selection model and participation equation in the double hurdle model 


\section{Abbreviations}

CultiAF: Cultivate Africa's Future; CVM: Contingent valuation method; FSTD: Fish solar tent dryer; GTA: Gender transformative approaches; IHS: Inverse hyperbolic sine; IMR: Inverse Mills ratio; MK: Malawi kwacha; NCRSH: National Committee on Research in the Social Sciences and Humanities; OLS: Ordinary Least Squares; UV: Ultraviolet; VSL: Village savings and loans; WTP: Willingness to pay

\section{Acknowledgements}

We acknowledge the financial and technical support from the Australian International Food Security Centre, ACIAR and the International Development Research Centre (IDRC), Ottawa, Canada, through the project on "Improved Processing and Marketing of Healthy Fish Products in Inland Fisheries in Malawi". All views expressed in this paper do not reflect the views of the funders or the institutions we belong to. All errors contained.

\section{Funding}

This paper has been produced through the financial support from the Australian International Food Security Centre, ACIAR and the International Development Research Centre (IDRC), Ottawa, Canada, through the project on 'Improved Processing and Marketing of Healthy Fish Products in Inland Fisheries in Malawi'.

\section{Authors' contributions}

LC conceived the research idea, analysed the data, interpreted the results and drafted the manuscript. GC entered and cleaned the data, analysed the data, participated in the interpretation of the results and edited the manuscript. LB, JB, and JN participated in the interpretation of the results and edited the manuscript. All authors read and approved the final manuscript.

\section{Competing interests}

The authors declare that they have no competing interests.

\section{Publisher's Note}

Springer Nature remains neutral with regard to jurisdictional claims in published maps and institutional affiliations.

\section{Author details}

${ }^{1}$ Department of Economics, Chancellor College, University of Malawi, P.O. Box 280, Zomba, Malawi. ${ }^{2}$ Department of Human Ecology, Chancellor College,University of Malawi , P.O. Box 280, Zomba, Malawi. ${ }^{3}$ Fisheries Research Unit, Department of Fisheries, Mangochi, Malawi. ${ }^{4}$ WorldFish Centre, Zomba, Malawi.

Received: 19 December 2016 Accepted: 3 January 2018

Published online: 15 January 2018

\section{References}

Affognon H, Mutungi C, Sanginga P, Borgemeister C (2015) Unpacking postharvest losses in sub-Saharan Africa: a meta-analysis. World Dev 66:49-68

Ayamga M, Yeboah R, Ayambila S (2016) An analysis of household farm investment decisions under varying land tenure arrangements in Ghana. J Agric Rural Dev Trop 117(1):21-34

Banda J, Simbeye J, Chisale E, Kanyerere G, Kamtambe K (2016) Quality analysis of Lake Malawi's Diplotaxodon fish species processed in solar tent dryer versus open sun drying, abstract. Int J Nutri Food Sci 3(7):1

Belsley DA (1991) Conditioning Diagnostics: Collinearity and Weak Data in Regression. New York. Wiley.

Béné C (2009) Are fishers poor or vulnerable? Assessing economic vulnerability in small scale fishing communities. J Dev Stud 45(6):911-933

Blumenschein K, Blomquist GC, Johannesson M, Horn N, Freeman P (2008) Eliciting willingness to pay without bias: evidence from a field experiment. Econ J 118(525):114-137

Brox J, Kumar R, Stollery K (2003) Estimating willingness to pay for improved water quality in the presence of item nonresponse bias. Am J of Agric Econ 85(2):414-428

Burbidge J, Magee L, Robb L (1988) Alternative transformations to handle extreme values of the dependent variable. J Am Stat Assoc 83(401):123-127

Burke WJ (2009) Fitting and interpreting Cragg's tobit alternative using Stata. Stata J 9(4):584-592

Carlsson F, Martinsson P (2007) Willingness to pay among Swedish households to avoid power outages: a random parameter tobit model approach. Energy J 28:75-89

Carson RT, Flores NT, Martin KM, Wright JL (1996) Contingent valuation and revealed preference methodologies: comparing the estimates for quasi-public goods. Land Econ 72:80-99

Chiwaula L, Jamu D, Chaweza R, Nagoli L (2012) The structure and margins of the Lake Chilwa fisheries in Malawi: a value chain analysis. WorldFish Project Report 2012-12. WorldFish, Penang

Chiweza AL (2005) Women's inheritance rights in Malawi: the role of district assemblies. Dev in Prac 15:83-89

Cho SH, Yen ST, Bowker JM, Newman DH (2008) Modeling willingness to pay for land conservation easements: treatment of zero and protest bids and application and policy implications. J Agr Appl Econ 40(1):267-285

Coastal Resources Center (2016) Value chain and fish postharvest loss assessment of four small pelagic lake fisheries in Malawi. Coastal Resources Center, Graduate School of Oceanography, University of Rhode Island, The Fisheries, Narragansett, Rl, p 91

Cochran WG (1977) Sampling techniques, 3rd edn. John Wiley \& Sons, New York

Cragg JG (1971) Some statistical models for limited dependent variables with application to the demand for durable goods. Econometrica 39:829-844

Diamond PA, Hausman JA (1994) Contingent valuation: is some number better than no number. J Econ Perspect 8(4):45-64 
Doe PE, Ahmed M, Muslemuddin M, Sachithananthan K (1977) A polythene tent dryer for improved sun drying of fish. Food Technol Aust 29:437-441

Donaldson C, Jones AM, Mapp TJ, Olson JA (1998) Limited dependent variables in willingness to pay studies: applications in health care. Appl Econ 30(5):667-677

FAO (2016) The state of world fisheries and aquaculture 2016. Contributing to food security and nutrition for all. FAO, Rome GoM (2008) Gender policy. Ministry of Women and Child Development, Lilongwe

Gordon HS (1954) The economic theory of a common property resource: the fishery. J Polit Econ 62:124-142

Greene W (2008) Discrete choice modelling. In: Mills T, Patterson K (eds) Palgrave handbook of econometrics, Applied econometrics, vol 2. Palgrave, London

Heckman J (1979) Sample selection bias as a specification error. Econometrica 47:153-161

Horowitz JK, McConnell KE (2002) A review of WTA/WTP studies. J Environ Econ Manag 44(3):426-447

Kawiya C (2017) Economic Assessment of the fish solar tent dryers in Malawi. Master of Arts in Economics Thesis, Department of Economics, University of Malawi, Zomba

Lancaster K (1966) A new approach to consumer theory. J Polit Econ 74(2):132-157

Leung SF, Yu S (1996) On the choice between sample selection and two-part models. J Econometrics 72:197-229

Lwanga SK, Lemeshow S (1991) Sample size determination in health studies: a practical manual. World Health Organisation, Geneva

Madden D (2008) Sample selection versus two-part models revisited: the case of female smoking and drinking $J$ Health Econ 27:300-307

Martínez-Espiñeira, R (2006) A Box-Cox Double-Hurdle model of wildlife valuation: The citizen's perspective. Ecological Economics, 58(1), 192-208, https://doi.org/10.1016/j.ecolecon.2005.07.006

McFadden D (1980) Econometric models for probabilistic choice among products. J Bus 53(3):S13-29.

McFadden DL (1984) Econometric analysis of qualitative response models. In: Griliches Z, Intriligator MD (eds) Handbook of econometrics, vol 2. North Holland, Amsterdam, pp 1395-1457

Nagoli J, Chiwona-Karltun L (2017) Uncovering human social networks in coping with Lake Chilwa recessions in Malawi. J Environ Management 192:134-141

Newman C, Henchion M, Matthews A (2003) A double-hurdle model of Irish household expenditure on prepared meals. Appl Econ 35(9):1053-1061

Ngwira N (2001) Study on women's property and inheritance rights in Malawi. Field report no.1. Chancellor College, Gender Studies Unit, Zomba

Olokor JO, Omojowo FS (2009) Adaptation and improvement of a simple solar dryer to enhance fish production. Nature Sci 7:10-14

Padi A, Addor JA, Nunfam VF (2015) An econometric model of factors influencing households' willingness to pay for improved solid waste management service within the Sekondi-Takoradi metropolis in the western region of Ghana. J Econ Sustainable Dev 6(16):15-29

Parfitt J, Barthel M, Macnaughton S (2010) Food waste within food supply chains: quantification and potential for change to 2050. Philos T R Soc B 365(1564):3065-3084

Sablani SS, Rahman MS, Haffar I et al (2003) Drying rates and quality parameters of fish sardines processed using solar dryers. Agric Mar Sci 8(2):79-86

Sinnig MG (2011) Determinants of savings and remittances: empirical evidence from immigrants to Germany. Rev Econ Household 9:45-67

Solgaard HS, Yang Y (2011) Consumers' perception of farmed fish and willingness to pay for fish welfare. Brit Food J 113(8):997-1010

Tobin J (1958) Estimation of relationships for limited dependent variables. Econometrica 26:24-36

Venkatachalam L (2004) The contingent valuation method: a review. Environ Impact Asses 24:89-124

Yu X, Abler D (2010) Incorporating zero and missing responses into CVM with open-ended bidding: willingness to pay for blue skies in Beijing. Environ Dev Econ 15:535-556

Zongo B, Diarra A, Barbier B, Zorom M, Yacouba H, Dogot T (2015) Farmers' practices and willingness to adopt supplemental irrigation in Burkina Faso. Int J Food Agric Econ 3(1):101-117

\section{Submit your manuscript to a SpringerOpen ${ }^{\circ}$ journal and benefit from:}

- Convenient online submission

- Rigorous peer review

- Open access: articles freely available online

- High visibility within the field

- Retaining the copyright to your article 